\title{
Brevity is the soul of wit or psychogeriatrics is growing up: new Brief Report category for international psychogeriatrics
}

This brief editorial is written at the beginning of a new calendar year and it is typical for this time to ponder what changes the new year will bring. One exciting change for International Psychogeriatrics (IPG) is the introduction of a new category of paper, the Brief Report.

As soon as this editorial appears in First View the new category will be open for submissions in ScholarOne. The updated IPG instructions for contributors will describe the Brief Report as a paper category, which should be no longer than 1,500 words with no more than three tables and figures and a maximum of 15 references. The abstract should be unstructured and not exceed 200 words. The Brief Report category will be peer reviewed and will follow the same style and demonstrate the same quality as original research manuscripts, so is expected to contain empirical data. This is the first time in many years that the editorial team of IPG, with support from the IPA President and IPA Executive, decided to introduce a new paper category. So what are the motives for this other than the wind of change at the beginning of a new calendar year?

The main compelling reason is to give authors more flexibility and choice to find the most suitable category for reporting their research. The Brief Report category offers authors the opportunity to share new and innovative research, similar to the "hot topics" category common at many scientific conferences. As so often with innovative approaches the body of work or evidence might still be limited and therefore the Brief Report offers a better fit than a longer original research paper. This category is increasingly common in scientific journals and some other journals focusing on aging or mental health, offer the Brief or Short Report or Brief or Short Communications category as well.

The introduction of this new category also responds to the fact that our discipline of psychogeriatrics (also known as old age psychiatry) is slowly growing up and finding its place amongst the neurosciences. With the global and collaborative ongoing development of more reliable biomarkers, for example in imaging, laboratory sciences, or neuropsychology (Perneczky and Kurz, 2012; Leuzy et al., 2014) increasingly more often these modern diagnostic and management tools are incorporated not only in psychogeriatric clinical research, but also start to be used in clinical care. This trend will also help to grow the budding focus on preventative strategies to protect mental health in middle-aged people at the doorstep to older age, but also throughout old age as well.

Together with introducing more modern technology and health promotion strategies (Kurz et al., 2013; Lam and Cheng, 2013; Dodge et al., 2014) these developments will help to empower consumers and families and respond effectively to growing expectations of aging communities. No doubt these newer trends will also help to play an important role in the ongoing quest to destigmatize the area of aged mental health. We believe that the new Brief Report category will make it easier to report and therefore promote innovative psychogeriatric research, and that this in turn will help the discipline of psychogeriatrics to meet challenges and opportunities ahead (Wang et al., 2013; Fernandes et al., 2015). We look forward to showcasing Brief Reports that will excite IPA members and IPG readers.

\section{Conflict of interest}

NT Lautenschlager is the Editor-in-Chief of IPG and therefore this editorial was assigned to one of the Deputy Editors of IPG for the editorial review and approval process.

\section{NiCOLA T. LAUTENSCHLAGER}

Department of Psychiatry, Academic Unit for Psychiatry of Old Age, the University of Melbourne NorthWestern Mental Health, Melbourne Health, Melbourne, Australia

School of Psychiatry and Neurosciences and WA Centre for Health \& Ageing, the University of Western Australia Email: nicolatl@unimelb.edu.au

\section{References}

Dodge, H. H., Ybarra, O. and Kaye, J. A. (2014). Tools for advancing research into social networks and cognitive 
function in older adults. International Psychogeriatrics, 26, 533-539.

Fernandes, L. et al. (2015). That state of psychogeriatrics in Europe: challenges and opportunities in six European countries. International Psychogeriatrics, 27, 1243-1246.

Kurz, A., Clare, L. and Lautenschlager, N. T. (2013). Add life to years: psychosocial interventions for people with cognitive disorders. International Psychogeriatrics, 25, 1389-1391.

Lam, L. C. W. and Cheng, S. T. (2013). Maintianing long-term adherence to lifestyle interventions for cognitive health in later life. International Psychogeriatrics, 25, 171-173.
Leuzy, A., Zimmer, E. R., Bhat, V., Rosa-Neto, P. and Gauthier, S. (2014). Imaging biomarkers for amyloid: a new generation of probes and what lies ahead. International Psychogeriatrics, 27, 12431246.

Perneczky, R. and Kurz, A. (2012). Dealing with uncertainty: biomarkers for the early detection of Alzheimer's disease. International Psychogeriatrics, 24, 1533-1535.

Wang, H. et al. (2013). The state of psychogeriatrics in different regions of the world: challenges and opportunities. International Psychogeriatrics, 25, 15631569. 